Submission ID: 43852

\title{
A New Approach to the Analysis of Gas Anomalies in the Subsoil Geosphere for Oil and Gas Exploration
}

O.K. Navrotsky* (JSC "NNIIGG"), A.N. Zotov (LLC "LukBelOil"), A.M. Dotsenko (FGBOU VO "Saratov National Research University named after NG Chernyshevsky")

\section{SUMMARY}

For oil companies operating in relatively small license areas, it is quite difficult to take advantage of all the scientific methods for solving their problems in terms of scientific, organizational, financial positions. In this paper, the authors share the experience of integrating structural geomorphological studies and gas surveying that led to the discovery of an oil field in the northwestern part of the Caspian depression The results of the work allowed us to formulate a new principle for interpretation of gas-geochemical testing of local objects in the forecast of oil and gas potential: areas that are characterized by a minimal hydrocarbon geochemical background and minimal tectonic tension are promising in the oil and gas respect. Special gas-geochemical (during August-December) studies at the open field showed that hydrogen does not exist in its subsoil gas.

Obviously, we need to make some clarification - the noted regularity is characteristic for territories with a direct character of the relief. In this case, the correlation of the structural plan of the deposits of the Bobrikovsky age in which the hydrocarbon depositsare detected and the relief is confirmed by high values of the correlation coefficient (0.7). 
О новом подходе к интерпретации газовых аномалий в подпочвенной геосфере при поисках нефти и газа

О.К. Навроцкий* (АО НВНИИГГ), А.Н. Зотов (ООО «ЛукБелОйл»), А.М. Доценко (ФГБОУ ВО «Саратовский национальный исследовательский государственный университет имени Н.Г. Чернышевского)

\section{Введение}

Для нефтяных компаний, работающих сравнительно на небольших лицензионных участках, воспользоваться всем достигнутым научным арсеналом для решения своих задач достаточно сложно по научным, организационным, финансовым позициям. В настоящей работе авторы делятся опытом комплексирования структурно-геоморфологических исследований и газометрической съемки, которые привели к открытию месторождения нефти в северо-западной части Прикаспийской впадины (рис.1)

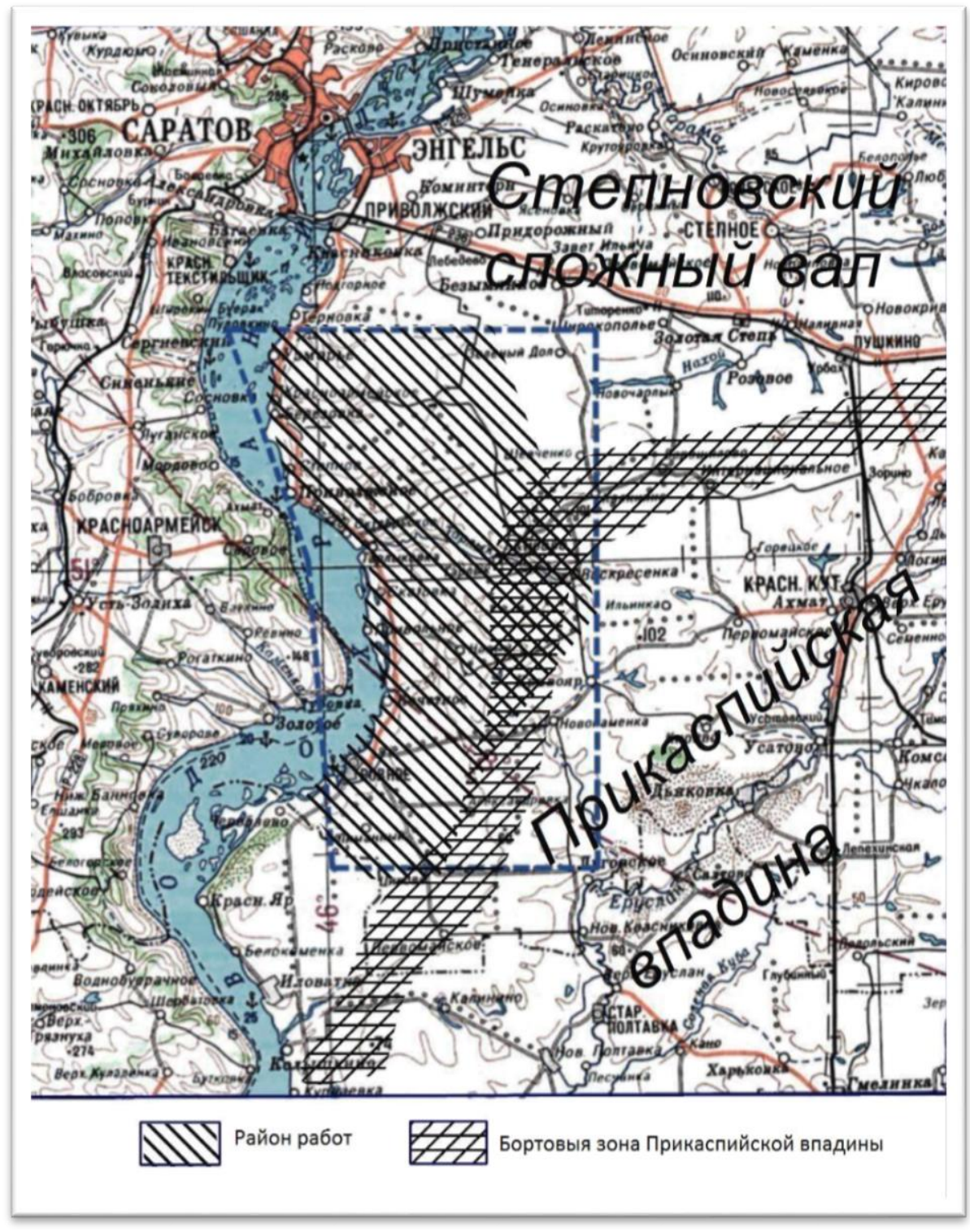

Рисунок 1. Обзорная схема территории исследования 


\section{Подход к интерпретации газовых аномалий в подпочвенной геосфере}

Результаты работ заставили пересмотреть взгляды на роль разломной тектоники и неотектоники (либо как своеобразного «насоса», осуществляющего перекачку флюидов из окружающих участков в зоны повышенной трещиноватости, либо как участки релаксации напряжений, в которых механическая энергия переходит в тепловую, что обеспечивает низкотемпературное преобразование органического вещества до углеводородов) и роль газометрической съемки, идея применения которой для прогнозирования нефтегазоносности принадлежит В.А. Соколову и изложена в ряде фундаментальных трудов $[1,2,3,4]$.

Для исследуемой территории, на основе фотоматериалов масштаба от 1:25 000 до высотных аэрофотоснимков масштаба 1:100 000 была составлена схема геодинамической напряженности (трещиноватость, денудационные и эрозионные уступы, перехваты верховьев эрозионных врезов, линеаментная сеть как отражение разрывной тектоники или зон дилатансий, рис.2). На этой же схеме показаны месторождения нефти и газа.

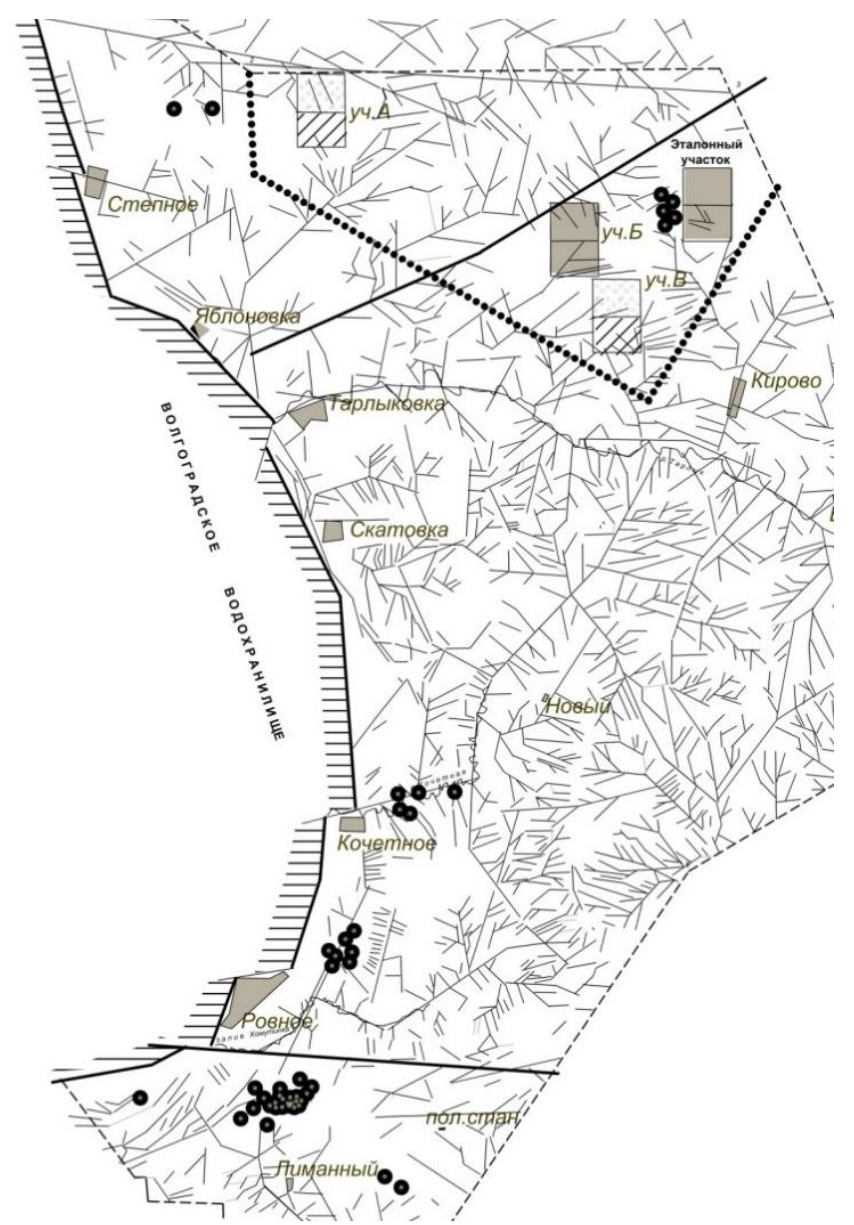

Рисунок 2. Геодинамическая напряженность (линеаментная сеть) и месторождения в северозападной части Прикаспийской впадинь

Условные обозначения: - продуктивные скважины; А, Б, В - тестируемые участки.

В работе делается вывод далеко не соответствующей характеру стандартных объяснений для системы «разломы↔нефтегазоносность»: месторождения находятся вне зон геодинамических напряжений - зон формирования современной линеаментной сети и узлов [5].

В соответствии с выявленными геофизическими методами структурами (А,Б,В) были поставлена газометрическая съемка, которая заключалась в бурении неглубоких (до 2 м) скважин и отборе газовых проб и их последующем хроматографическом анализе. В газах определялись метан и его гомологи, гелий, водород, кислород, двуокись углерода, азот [6]. 
В пределах открытого месторождения было так же проведено газометрическое зондирование и этот участок был принят за эталон.

Следует отметить, что эффективность приповерхностной газовой съемки оценивалась не всеми исследователями одинаково. Периоды расцвета прямых геохимических методов сменялись периодами упадка.

Фундаментальные работы В.А. Соколова, как уже упоминалось, свидетельствовали о том, что над продуктивными структурами содержание метана и его газообразных гомологов зачастую оказываются выше, чем над «пустыми». Однако проблемы интерпретации приповерхностных газовых аномалий до настоящего времени остаются достаточно серьезными [7]:

- прямой связи продуктивности скважин с величиной значений газосодержания не отмечается;

- по результатам последних лет складывается впечатление, что наиболее продуктивные участки характеризуются пространственно консолидированным, невысоким по абсолютным значениям газосодержания геохимическим полем.

Результаты работ показали, что эталонный участок характеризуется минимальным геохимическим газовым фоном и минимальной геодинамической напряженностью. Из всех других исследуемых участках «А, Б, В» только участок «Б» приближался по названным параметрам к эталонному участку (табл.1)

Таблица 1. Сравнительный анализ газогеохимического фона (об.\%) в пределах эталонного участка (месторождения) и выявленных структур.

\begin{tabular}{|l|l|l|l|l|l|}
\hline & $\begin{array}{l}\text { Метан } \\
\mathrm{n} \mathrm{x} 10^{-6}\end{array}$ & $\begin{array}{l}\text { Пропан } \\
\mathrm{n} \mathrm{x} 10^{-6}\end{array}$ & $\begin{array}{l}\text { Н-бутан } \\
\mathrm{n} \times 10^{-6}\end{array}$ & $\begin{array}{l}\text { Гелий } \\
\mathrm{n} \times 10^{-5}\end{array}$ & $\begin{array}{l}\text { Водород } \\
\mathrm{n} 10^{-5}\end{array}$ \\
\hline $\begin{array}{l}\text { Эталонный } \\
\text { участок }\end{array}$ & 72 & 3,5 & 3 & 45 & 22 \\
\hline Участок А & 108 & 5 & 7 & 44 & 58 \\
\hline Участок Б & 70 & 4 & 2 & 40 & 15 \\
\hline Участок В & 386 & 4 & 5 & 45 & 21,4 \\
\hline
\end{tabular}

В пределах этого участка была пробурена глубокая скважина и в породах бобриковского возраста открыта промышленная нефтяная залежь.

Результаты работ позволили сформулировать новый принцип интерпретации газогеохимического тестирования локальных объектов при прогнозе нефтегазоносности [8]: перспективными в нефтегазоносном отношении считают площади, которые характеризуются минимальным углеводородным геохимическим фоном и минимальной тектонической напряжённостью.

\section{Выводы}

Последующий газогеохимический мониторинг (май-декабрь 2014г.) в пределах открытой залежи показал отсутствие водорода в специально пробуренной геохимической скважине, что свидетельствует о «спокойном» характере блока (структуры), в котором сформирована нефтяная залежь.

С нашей точки зрения, представленные материалы достаточно аргументированно показывают необходимость серьезного обсуждения подхода к поиску месторождений нефти и газа на основе использования выше названных методических приемов. Очевидно, надо сделать некоторое уточнение - отмеченная закономерность выявлена для территорий с прямым характером рельефа. В данном случае, соотношение структурного плана отложений бобриковского возраста, в которых обнаружена залежь УВ, и рельефа подтверждается 
высокими значениями коэффициента корреляции $(0,7)$. Для обращенных форм рельефа требуется специальная постановка работ.

\section{Библиография}

1. Геохимические, нефтегазопоисковые исследования в Европейской части СССР. М.: Недра, $1975,156 \mathrm{c}$.

2. Соколов В.А. Геохимия природных газов. - М.: Недра, 1971, 334 с.

3. Зорькин Л.М., Старобинец И.С., Стадник Е.В. Геохимия природных газов нефтегазоностных бассейнов. - М.: Недра, 1984, 248 с.

4. Комплексный анализ данных геохимических поисков нефти и газа.- М.: Недра, 1981, 268 с.

5. Зотов А.Н., Навроцкий О.К., Бондаренко В.В. Трещиноватость современного рельефа и нефтегазоносность (на примере северо-западного обрамления Прикаспийской впадины). Петрофизика сложных коллекторов: проблемы и перспективы 2015. Сборник статей/ Сост.Б.Н.Еникеев - М.:000 «ЕАГО Геомодель»,2015.-381с.-С. 334-339. ISBN № 978-946282-173-6].

6. ГОСТ 23781-87 «Газы горючие природные. Хроматографический метод определения компонентного состава».

7. Заватский М.Д. Изучение полей концентраций углеводородных газов в поверхностных природных сорбентах в связи с поисками и разведкой залежей нефти и газа в Западной Сибири. Автореферат, диссертация, 2009

8. Зотов А.Н., Навроцкий О.К., Бондаренко В.В. Способ геохимического тестирования локальных объектов при прогнозе нефтегазоносности. Патент на изобретение №2577801 Государственный реестр изобретений Российской Федерации, 17.02.2016

\section{References}

1. Geochemical, oil and gas exploration in the European part of the USSR. M .: Nedra, 1975, $156 \mathrm{p}$.

2. Sokolov V.A. Geochemistry of natural gases. - Moscow: Nedra, 1971, 334 p.

3. Zorkin LM, Starobinets IS, Stadnik EV Geochemistry of natural gases in oil and gas basins. Moscow: Nedra, 1984, 248 p.

4. Complex analysis of geochemical prospecting data for oil and gas .- M .: Nedra, 1981, $268 \mathrm{p}$.

5. Zotov AN, Navrotsky OK, Bondarenko V.V. Fracture of the modern relief and oil and gas content (in terms of the north-western border of the Caspian depression). Petrophysics of Complex Collectors: Problems and Prospects 2015. Collection of Articles / Compiled by B.Enikeev-M.: 000 "EAGO Geomodel", 2015.-381s.-C. 334-339. ISBN No. 978-94-6282-173-6].

6. GOST 23781-87 "Gases combustible natural. Chromatographic method for determining the component composition. "

7. Zavatsky M.D. Study of concentration fields of hydrocarbon gas in surface natural sorbents in connection with prospecting and exploration of oil and gas deposits in Western Siberia. Abstract, thesis, 2009

8. Zotov AN, Navrotsky OK, Bondarenko V.V. Method of geochemical testing of local objects in the forecast of oil and gas potential. Patent for invention № 2577801 State register of inventions of the Russian Federation, 02/17/2016 